Epidemiología, Medellín, Colombia; ${ }^{5}$ IPS Universitaria Servicios de Salud Universidad de Antioquia, Rheumatology, Medellin, Colombia; ${ }^{6}$ Hospital San Vicente Fundación, Rheumatology, Medellin, Colombia

Background: Giant cell arteritis (GCA) is a large vessel vasculitis (LVV) that affects mostly the elderly (1). Temporal artery biopsy (TAB) has been defined as the gold standard, although this has come to question (3). EULAR guidelines recommended non-invasive imaging techniques such as the temporal artery Doppler ultrasound to aid in LVV diagnosis (2). The characterization of GCA in Latin American countries, and specifically in Colombia, is scarce.

Objectives: To perform a clinical, demographical, histopathological, and radiological characterization of

Colombian GCA patients.

Methods: Retrospective data from GCA patients at two teaching hospitals in Medellín, Colombia, was collected. A bioethics committee previously approved the research protocol. Inclusion criteria: diagnosis of GCA, based on clinical characteristics or imaging/biopsy findings. Exclusion criteria: HIV diagnosis, paraneoplastic large vessel vasculitis. Clinical, radiological, and histopathological variables were selected based on the clinicians' expertise and the 2018 EULAR recommendations for a core data set to support observational research and clinical care in giant cell arteritis (3). The data were analyzed in SPSS v22.0 (IBM, USA).

Results: Twenty-two patients were collected. Demographical and clinical characteristics are summarized in Table 1. Most patients were women (68.1\%), with a mean age of 71.8 years, mean duration of symptoms of 5.3 months. In the cranial form of the disease, the most common symptoms were headache and jaw claudication (95\% and $68 \%$ ). Six patients experienced visual loss: complete unilateral visual loss in two, partial unilateral in two, complete bilateral in one, and partial bilateral in one patient.

Sixteen patients $(72.7 \%)$ underwent TAB; the most common finding was mononuclear infiltrate and internal elastic fragmentation in $43.7 \%$ of the biopsies. Giant cells were observed in 6 biopsies (37.5\%). Doppler ultrasound was performed in 19 patients $(86.35 \%)$, finding intima-media thickening and the halo sign $t$ in 7 patients $(36.8 \%)$

Table 1. Demographical and clinical characteristics

\begin{tabular}{lc}
\hline Characteristic & $\mathbf{n = 2 2}$ \\
\hline Mean age (years SD) & $71.8(10.6)$ \\
Female sex $\mathrm{n}(\%)$ & $15(68.1 \%)$ \\
Mean symptoms duration (months \pm SD) & $5.3 \pm 6.8$ \\
Mestizo $\mathrm{n}(\%)$ & $20(90 \%)$ \\
Headache $\mathrm{n}(\%)$ & $21(95.4 \%)$ \\
Jaw claudication $\mathrm{n}(\%)$ & $15(68.1 \%)$ \\
Weight loss $\mathrm{n}(\%)$ & $13(59 \%)$ \\
Scalp sensitivity $\mathrm{n}(\%)$ & $11(50 \%)$ \\
Fever $\mathrm{n}(\%)$ & $8(36.3 \%)$ \\
Presence of polymyalgia rheumatica $\mathrm{n}(\%)$ & $7(31.8 \%)$ \\
Visual loss $\mathrm{n}(\%)$ & $6(27.2 \%)$ \\
Amaurosis fugax $\mathrm{n}(\%)$ & $1(4.5 \%)$ \\
Glucocorticoids n (\%) & $22(100 \%)$ \\
Pulse $\mathrm{n}(\%)$ & $8(36.3 \%)$ \\
Mean dose (mg \pm SD) & $47.1 \pm 16.7$ \\
Methotrexate $\mathrm{n}(\%)$ & $17(77.7 \%)$ \\
Azathioprine $\mathrm{n}(\%)$ & $2(9 \%)$ \\
Tocilizumab $\mathrm{n}(\%)$ & $1(4.5 \%)$ \\
&
\end{tabular}

Conclusion: In this GCA cohort, the main phenotype was cranial GCA, with $95 \%$ of the patients presenting with headache. The most common imaging study performed was Doppler ultrasound of temporal arteries, with intima-media thickening and halo sign being the most common findings. The mainstay of treatment was glucocorticoids with methotrexate as a sparing agent. To our knowledge, this study is the first to perform a specific characterization of GCA patients in the Colombian population, and it can represent the foundation of further research for these patients.

REFERENCES:

[1] Lazarewicz K, Watson P. Giant cell arteritis. BMJ. 2019 May 30;365:I1964.

[2] Dejaco C, Ramiro S, Duftner C, Besson FL, Bley TA, Blockmans D, et al. EULAR recommendations for the use of imaging in large vessel vasculitis in clinical practice. Ann Rheum Dis. 2018 May;77(5):636-43.

[3] Ehlers L, Askling J, Bijlsma HWJ, Cid MC, Cutolo M, Dasgupta B, et al. 2018 EULAR recommendations for a core data set to support observational research and clinical care in giant cell arteritis. Ann Rheum Dis. 2019;78(9):1160-6.

Disclosure of Interests: None declared

DOI: 10.1136/annrheumdis-2021-eular.2436

\section{AB0375 EXTERNAL VALIDATION OF THE GIANT CELL ARTERITIS PROBABILITY SCORE IN THE NETHERLANDS}

L. M. Neuman ${ }^{1}$, M. Van Nieuwland ${ }^{1}$, M. Vermeer ${ }^{2}$, D. Boumans ${ }^{1}$, E. Colin ${ }^{1}$, C. Alves ${ }^{1}{ }^{1}$ Hospital Group Twente, Rheumatology and Clinical Immunology, Almelo, Netherlands; ${ }^{2}$ Hospital Group Twente, ZGT Academy, Almelo, Netherlands

Background: Severe complications of giant cell arteritis (GCA), such as blindness and ischemic stroke, can be prevented by timely treatment. This requires early and accurate diagnosis. In 2019, Laskou et al. developed a clinical GCA probability score (GCAPS) that allows physicians to assess the probability of GCA at initial assessment. The GCAPS is suitable for easy implementation in daily practice. It has a high sensitivity $(95.7 \%)$ and specificity $(86.7 \%)$ at a cut-off value of 9.5 as proposed by Laskou et al.

Objectives: The aim of this study was to externally validate the GCAPS in a general hospital.

Methods: A retrospective cohort of patients with suspected GCA between January $1^{\text {st }} 2017$ and October $1^{\text {st }} 2019$ at Ziekenhuisgroep Twente (the Netherlands) was used. As the parameter extra-cranial artery abnormality was not available in our cohort, a modified version of the GCAPS was used (m-GCAPS). The m-GCAPS was compared to clinical diagnosis of a rheumatologist after six months in accordance with Laskou et al. The validity of the m-GCAPS was assessed by plotting a receiver operating characteristic (ROC) curve and assessing sensitivity and specificity for multiple cut-off values. For practical purposes, risk stratifications as proposed by Sebastian et al. (2020) were applied to our data (low-risk <9; intermediate-risk 9-12; high-risk >12).

Results: In our cohort, 40 GCA patients and 95 controls (suspected of GCA) had complete records and were therefore used for analysis. In the patient group, $29(72.5 \%)$ were female and mean (SD) age was $73.3(1.6)$. The area under the ROC curve (AUC) was $0.83(95 \% \mathrm{Cl} 0.75-0.91)$. At our optimal cut-off value of 10.5 , sensitivity was $80.0 \%$ and specificity was $75.8 \%$. In total, 5 patients and 45 controls were stratified as low, 7 patients and 35 controls as intermediate and 28 patients and 15 controls as high-risk.

Conclusion: The m-GCAPS showed good discrimination in our cohort. Risk stratification of patients looks promising, although cut-off values by Sebastian et al. might need optimization based on population and modification to the GCAPS. Colour Doppler ultrasound is recommended by EULAR as the first-choice diagnostic test to confirm GCA in case of high pre-test probability and exclude GCA for low pre-test probability. The (m-)GCAPS may aid in quantification of this pretest probability.

REFERENCES:

[1] Laskou F, Coath F, Mackie SL et al. A probability score to aid the diagnosis of suspected giant cell arteritis. Clin Exp Rheumatol. 2019;37 Suppl 1(2):104-8.

[2] Sebastian A, Tomelleri A, Kayani A et al. Probability-based algorithm using ultrasound and additional tests for suspected GCA in a fast-track clinic. RMD Open. 2020 Sep 1;6(3):e001297.

[3] Dejaco C, Ramiro S, Duftner $C$ et al. EULAR recommendations for the use of imaging in large vessel vasculitis in clinical practice. Ann Rheum Dis. 2018 May 1;77(5):636 LP - 643 .

Table 1. Cut-off values of the m-GCAPS stratified into risk categories as proposed by Sebastian et al. Sensitivity, specificity, positive predictive value (PPV) and negative predictive value (NPV) and the number of patients scoring above or below the cut-off values are described (optimal cut-off value in blue). The total number of patients with a score within low- (red), intermediate- (orange) and high- (green) risk categories are depicted.

\begin{tabular}{|c|c|c|c|c|c|c|c|c|c|c|}
\hline & $\begin{array}{c}\mathrm{GCA}+(\mathrm{N}) \\
\mathrm{N}=40\end{array}$ & $\begin{array}{c}\text { GCA- (N) } \\
N=95\end{array}$ & $\begin{array}{r}\mathrm{Sc} \\
\mathrm{m}-\mathrm{GC}\end{array}$ & $\begin{array}{l}\text { ore } \\
\text { CAPS }\end{array}$ & $\begin{array}{c}\text { GCA+ } \\
(\mathrm{N})\end{array}$ & $\begin{array}{c}\text { GCA- } \\
(\mathrm{N})\end{array}$ & $\begin{array}{l}\text { Sens. } \\
(\%)\end{array}$ & $\begin{array}{c}\text { Spec. } \\
(\%)\end{array}$ & $\begin{array}{l}\text { PPV } \\
(\%)\end{array}$ & $\begin{array}{l}\text { NPV } \\
(\%)\end{array}$ \\
\hline \multirow[t]{2}{*}{ Low-risk $<9$} & 5 (12.5\%) & 45 (47.4\%) & 5.5 & $\begin{array}{l}<5.5 \\
>5.5\end{array}$ & $\begin{array}{c}0 \\
40\end{array}$ & $\begin{array}{l}14 \\
81\end{array}$ & 100 & 14.7 & 33.1 & 100 \\
\hline & & & 8.5 & $\begin{array}{l}<8.5 \\
>8.5\end{array}$ & $\begin{array}{c}5 \\
35\end{array}$ & $\begin{array}{l}45 \\
50\end{array}$ & 87.5 & 47.4 & 41.2 & 90 \\
\hline $\begin{array}{l}\text { Intermediate- } \\
\text { risk }\end{array}$ & 7 (17.5\%) & 35 (36.8\%) & 9.5 & $\begin{array}{l}<9.5 \\
>9.5\end{array}$ & $\begin{array}{c}8 \\
32\end{array}$ & $\begin{array}{l}56 \\
39\end{array}$ & 80 & 58.9 & 45.1 & 87.5 \\
\hline \multirow[t]{2}{*}{$9-12$} & & & 10.5 & $\begin{array}{l}<10.5 \\
>10.5\end{array}$ & $\begin{array}{c}8 \\
32\end{array}$ & $\begin{array}{l}72 \\
23\end{array}$ & 80 & 75.8 & 58.2 & 90 \\
\hline & & & 11.5 & $\begin{array}{l}<11.5 \\
>11.5\end{array}$ & $\begin{array}{l}10 \\
30\end{array}$ & $\begin{array}{l}74 \\
21\end{array}$ & 75 & 77.9 & 58.8 & 88.1 \\
\hline $\begin{array}{l}\text { High-risk } \\
>9\end{array}$ & $28(70.0 \%)$ & 15 (15.8\%) & 12.5 & $\begin{array}{l}<12.5 \\
>12.5\end{array}$ & $\begin{array}{l}12 \\
28\end{array}$ & $\begin{array}{l}80 \\
15\end{array}$ & 70 & 84.2 & 65.1 & 87 \\
\hline \multirow{2}{*}{$>9$} & & & 14.5 & $\begin{array}{l}<14.5 \\
>14.5\end{array}$ & $\begin{array}{l}18 \\
22\end{array}$ & $\begin{array}{c}89 \\
6\end{array}$ & 55 & 93.7 & 78.6 & 83.2 \\
\hline & & & 19.5 & $\begin{array}{l}<19.5 \\
>19.5\end{array}$ & $\begin{array}{c}37 \\
3\end{array}$ & $\begin{array}{c}95 \\
0\end{array}$ & 7.5 & 100 & 100 & 72 \\
\hline
\end{tabular}




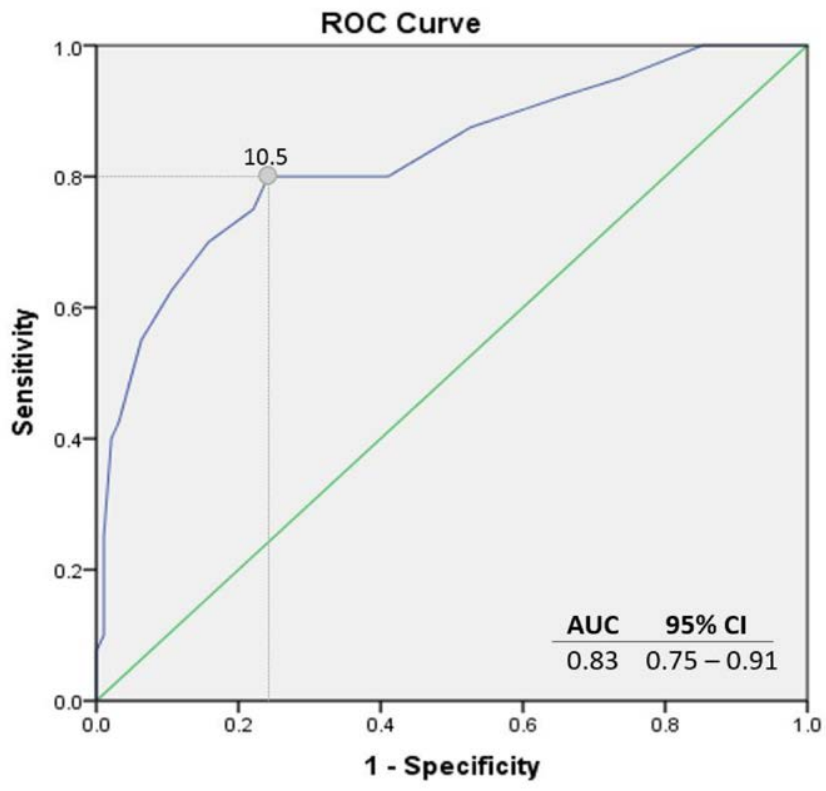

Figure 1. ROC curve depicting sensitivity and (1-) specificity. The AUC was $0.83(95.0 \% \mathrm{Cl}$ $0.75-0.91$ ) with an optimal cut-off value of 10.5 (sensitivity $80.0 \%$, specificity $75.8 \%$ ).

Disclosure of Interests: None declared DOI: 10.1136/annrheumdis-2021-eular.2466

\begin{tabular}{|l|l}
\hline AB0376 & LEVEL OF DIAGNOSTIC AND THERAPEUTIC \\
KNOWLEDGE, SKILLS AND COMPETENCIES IN GIANT \\
CELL ARTERITIS AMONG EMERGENCY MEDICAL \\
STAFF
\end{tabular}

C. Guillén-Astete $^{1}$, I. Perea-Fuentes ${ }^{2}$, L. Ayala-Terrados ${ }^{2}$, N. García-Montes ${ }^{3}$. ${ }^{1}$ Hospital Ramón y Cajal, Rheumatology, MADRID, Spain; ${ }^{2}$ CEU San Pablo, Medicine, Madrid, Spain; ${ }^{3}$ Hospital Ramón y Cajal, Emergency, Madrid, Spain

Background: Giant cell arteritis (GCA) is the most frequently diagnosed vasculitis in Spain. The highest incidence recorded in the country is 17 new cases per 100,000 inhabitants/year. Its delayed diagnosis exposes the patient to an increased risk of multiple ischaemic complications. Among them, vision loss has been reported in up to 1 in 6 cases. Most of these patients, according to unpublished local observations, presented with headache, visual disturbances or polymyalgic symptoms to an emergency department facility and were not correctly or prompted diagnosed.

Objectives: To determine the level of knowledge, skills and diagnostic and therapeutic competencies of the medical staff of multiple emergency departments in our city in regard to giant cell arteritis.

Methods: We designed an observational study based on a single survey carried out between February and March 2020 to medical staff from 12 emergency departments in the city of Madrid. Four private and eight public emergency departments were deliberately included. The selection of the surveyed staff was randomly selected to reach $50 \%$ of the total number of physicians in each department. A total of 229 surveys were distributed by e-mail. A total of 125 physicians responded (final response rate $54.5 \%$ ). Twenty-two physicians $(9.2 \%)$ did not respond to the request and the rest declined to participate, although they responded to the demographic section (35.8\%).

The survey included the following sections: respondent profile, knowledge of epidemiological aspects, identification of clinical manifestations, diagnostic and therapeutic skills, and educational interest.

Results: Forty respondents (33.6\%) worked in a privately managed emergency department and $79(66.4 \%)$ in a public centre. The mean age of respondents was 37.3 SD 5.9 years, and the proportion of women was $62.4 \%$. Mean length of service was 3.4 SD 1.2 years among physicians in private emergency departments and 5.7 SD 2.3 in a public management unit. Sixty-four respondents $(53.7 \%)$ were specialists in Family and Community Medicine, and 46 $(38.6 \%)$ in internal medicine. No significant differences in demographic characteristics were identified between respondents who agreed to participate and those who declined.
In regard to epidemiological knowledge, $50.6 \%$ of respondents were unable to identify the age group at highest risk of GCA, $32.7 \%$ did not recognise its predominance in the female sex, and $26 \%$ did not know the approximate incidence of the disease.

In terms of diagnostic suspicion, $46.2 \%$ of respondents were able to identify at least five clinical manifestations of the disease. Elevated ESR, CRP and the presence of anaemia were recognised as positive analytical data by $98.3 \%$, $85.7 \%$ and $57.7 \%$ of respondents, respectively. Ultrasonography of temporal arteries was identified by $97.5 \%$ of respondents as a useful diagnostic technique. One hundred and two respondents (81.6\%) indicated that they had not suspected GCA in the last month. In the last year, 34 respondents $(27.2 \%)$ reported having diagnosed the disease on at least one occasion. Regarding treatment, in cases of absence of ischaemic lesion $\mathbf{8 5 . 7 \%}$ indicated suboptimal corticosteroid therapy guidelines, however, $63.0 \%$ of the respondents self-rated their therapeutic skills as very good or excellent.

Finally, $88.2 \%$ of respondents expressed interest in participating in training programmes in diagnosis and treatment of GCA

Conclusion: There are important areas for improvement in knowledge, diagnostic skills and therapeutic competencies among emergency physicians in relation to the suspicion and management of GCA.

Disclosure of Interests: None declared

DOI: 10.1136/annrheumdis-2021-eular.2815

\section{AB0377 CLINICAL REVIEW OF 19 CASES WITH IDIOPATHIC AORTITIS - A SINGLE CENTRE STUDY}

M. J. Villar ${ }^{1}$, S. Sangle ${ }^{2}$, D. D'cruz ${ }^{2} .{ }^{1}$ Clinica Alemana, Reumatolog ía, Vitacura, Chile; ${ }^{2}$ Guys and St Thomas' Hospital NHS Foundation Trust, Louise Coote Lupus Unit, London, United Kingdom

Background: Aortitis is a group of disorders leading to inflammation in the aorta. When aortitis has no clinical evidence of systemic vasculitis, it is called idiopathic aortitis or clinically isolated aortitis (CIA).

There is no consensus on the management of CIA.

Objectives: Our purpose is to describe our cohort of patients with $\mathrm{CIA}$ and their response to treatment.

Methods: This is a retrospective analysis of 19 patients with CIA. All records of patients with $\mathrm{CIA}$ were analyzed and demographic variables, comorbidities, symptoms, images, histology, treatment

received, outcome and mortality were recorded. The description of quantitative variables was made using the median and the interquartile range (IQR).

Results: Nineteen patients were analyzed. Diagnosis was made by imaging in $18(94.7 \%)$, one patient was diagnosed by histology after aortic root surgery. Patient characteristics are detailed in Table 1.

The median duration of follow- up was 38 months (IQR 43). Seven patients $(36.8 \%)$ had constitutional symptoms including fever, weight loss, sweats and fatigue. $4(21.05 \%)$ presented with back or abdominal pain for a mean duration of 3 months (SD 0.81 ) before the diagnosis. In $8(42.1 \%)$ patients the diagnosis was made incidentally.

All patients had negative treponema, hepatitis $\mathrm{B}$, hepatitis $\mathrm{C}$ and Human Immunodeficiency Virus (HIV) serology.

All patients had negative autoimmune serology included ANCA. Interestingly $4(21.05 \%)$ had positive lupus anticoagulant without other manifestation of antiphospholipid syndrome.

The type of aortic involvement was aortitis in 10 patients $(52.6 \%)$, inflammatory aneurysm in $8(42.1 \%)$ and dissection in $1(5.2 \%)$.

Seven (36.8\%) patients had thoracic and abdominal aorta involvement, 6 (31.5\%) only thoracic aorta and 6 (31.5\%) only abdominal aorta.

Aortic histology was obtained in 5 patients, 2 had necrotizing arteritis with giant cell pattern and 2 had lymphoplasmacytic pattern. Temporal artery biopsy was done in one patient and the result was negative for GCA.

All patients received corticosteroids as a remission inducing agent, 12 $(63.1 \%)$ received methotrexate and $2(10.5 \%)$ mycophenolate. 2 patients died $(10.5 \%)$.

The median prednisone dose at the beginning was $20 \mathrm{mg}$ (IQR 20) and at remission was $5 \mathrm{mg}$ (IQR 20). 41.6\% (5/12) of patients treated with steroids plus methotrexate were able to stop steroids without reactivation over a median follow-up time of 23.5 months (IQR 31). (Table 2.)

Details of treatment, ESR and CRP pre and post treatment is shown in Figure 1.

Seven patients $(36.8 \%)$ had follow-up imaging, none of them showed active inflammation, new aneurysm, dissection or disease progression.

Conclusion: Treatment of isolated aortitis with steroids and methotrexate was effective resulting in clinical and laboratory improvement and allowed cessation or decrease in steroids to $5 \mathrm{mg}$ or less in $83 \%$ of patients. This therapeutic approach may be useful in patients with CIA. 